\title{
Dural ectasias in ankylosing spondylitis
}

\section{Pankaj Bansal $^{1}$ (D) $\cdot$ Trevor Rich $^{1}$}

Received: 3 July 2020 /Revised: 11 August 2020 / Accepted: 12 August 2020 / Published online: 18 August 2020

(C) International League of Associations for Rheumatology (ILAR) 2020

\section{Presentation}

Seventy-nine-year-old male with history of untreated juvenile ankylosing spondylitis (AS) for 65 years, presented with 10year history of insidious-onset bilateral lower extremities paresthesia and saddle anesthesia. He had surgery for benign prostatic hyperplasia 5 years ago, and developed urinary incontinence post-surgically, which has persisted. He denied joint or back pain. C-reactive protein was normal. X-rays showed sacroiliac joint fusion and bamboo spine (supplementary image). Nerve conducted studies (NCS) revealed primarily axonal motor and sensory peripheral neuropathy but no radiculopathy. Magnetic resonance imaging (MRI) revealed dural ectasias in the lumbar spine (Fig. 1). Patient was evaluated by neurology and neurosurgery, and after discussion with patient, given the lack of typical features of cauda equine syndrome (CES) on the NCS and non-progressive symptoms, non-surgical intervention was preferred. Patient was initiated on gabapentin with improvement in symptoms.

\section{Discussion}

Development of dural ectasias or arachnoid cysts is a rare complication of longstanding AS and can lead to CES [1]. Chronic inflammation in AS leading to erosions of posterior elements of lumbosacral spine can cause enlargement of the spinal dural sac. Further, extension of inflammation to the dura in AS can cause adhesion of the dura to the surrounding structures. Excessive spinal fluid pressure and nerve root compression from the dural ectasias can lead to nerve root damage leading to progressive CES, which typically manifests as progressive lumbosacral plexopathy with subsequent urinary and bowel dysfunction [2]. Treatment options are limited with corticosteroids and non-steroidal anti-inflammatory drugs not shown to be efficacious [3]. Surgical interventions such as laminectomy, lumboperitoneal shunting, and medical management including anti-tumor necrosis factor agents have shown variable success in improving symptoms although population outcome measures largely remain to be assessed [3, 4].

Electronic supplementary material The online version of this article (https://doi.org/10.1007/s10067-020-05348-1) contains supplementary material, which is available to authorized users.

Pankaj Bansal

Bansal.pankaj@mayo.edu

1 Mayo Clinic Health System, 1400 Bellinger street, Eau Claire, WI 54702, USA 
Fig. 1 Sagittal (a, b) and axial (c, d) T2-weighted magnetic resonance imaging with multiple dural ectasias and widening of spinal canal. Axial computed tomography (e) showing widening of spinal canal, and multiple erosions on the spinous process and laminae

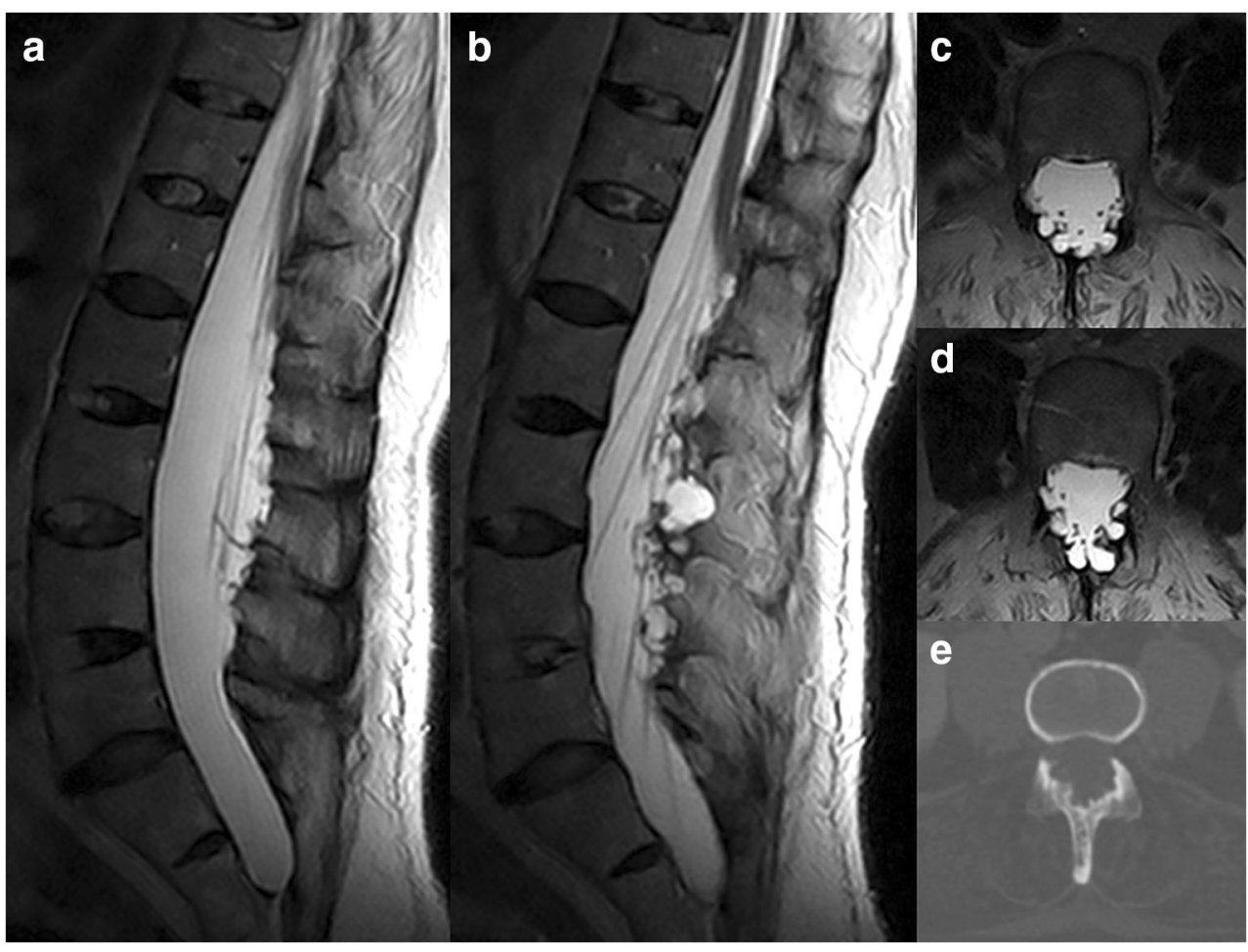

Author contributions Pankaj Bansal: writing initial manuscript, literature review, image editing

Trevor Rich: reviewing and revising manuscript, literature review

\section{Compliance with ethical standards}

\section{Disclosures None.}

Ethics approval The Mayo Clinic Institutional Review Board (IRB) acknowledges that based on the responses submitted for this new activity through the Mayo Clinic IRBe Human Subjects Research Wizard tool, and in accordance with the Code of Federal Regulations, 45 CFR 46.102, the above noted activity does not require IRB review.

Patient consent Written informed consent was obtained from the patient for publishing this material.

\section{References}

1. Matthews WB (1968) The neurological complications of ankylosing spondylitis. J Neurol Sci 6(3):561-573. https://doi.org/10.1016/ 0022-510x(68)90035-x

2. Confavreux C, Larbre JP, Lejeune E, Sindou M, Aimard G (1991) Cerebrospinal fluid dynamics in the tardive cauda equina syndrome of ankylosing spondylitis. Ann Neurol 29(2):221-223. https://doi. org/10.1002/ana.410290220

3. Ahn NU, Ahn UM, Nallamshetty L, Springer BD, Buchowski JM, Funches L et al (2001) Cauda equina syndrome in ankylosing spondylitis (the CES-AS syndrome) : meta-analysis of outcomes after medical and surgical treatments. J Spinal Disord 14:427-433. https://doi.org/10.1097/00002517-200110000-00009

4. Cornec D, Devauchelle Pensec V, Joulin SJ, Saraux A (2009) Dramatic efficacy of infliximab in cauda equina syndrome complicating ankylosing spondylitis. Arthritis Rheum 60(6):1657-1660. https://doi.org/10.1002/art.24597

Publisher's note Springer Nature remains neutral with regard to jurisdictional claims in published maps and institutional affiliations. 